\title{
Estudio de la explotación artesanal en el lecho del río Cesar en el sector norte de Guacoche-Guacochito
}

Calixto Ortega', Dino Manco², Elías Rojas ${ }^{3}$

\section{Resumen}

En el río Cesar, departamento del Cesar, en el sector norte de Guacoche-Guacochito desde hace aproximadamente diez años se está explotando artesanalmente de manera incontrolada, sin planificación y si estandarización materiales de construcción (material de arrastre) destinado a obras urbanísticas en la ciudad de Valledupar, Cesar, permitiendo así el deterioro ambiental y geotécnico de las riveras de los ríos mencionados. Este estudio tiene como objetivo caracterizar los aspectos más relevantes de la explotación artesanal en el lecho del río Cesar en el sector norte de Guacoche-Guacochito en el departamento del Cesar. Se recopiló la información existente sobre la zona de interés mediante estudios geológicos, hidrológicos, monografías, como el Informe geológico preliminar de la cuenca del río Cesar, Atlas ambiental del departamento del Cesar, entre otros. Se emplea el método de minería a cielo abierto de avance sobre las playas y depósitos de material dentro del río. Conclusiones: la cual el material se extrae en áreas que ya han sido recargadas por los aportes en la creciente del río en épocas de sequía. El mecanismo es que al llegar la época de verano se forman las terrazas, lo cual permite la entrada a volquetas con capacidades de $6 \mathrm{~m}^{3} \mathrm{y}$ palas manuales.

Palabras clave: Guacoche, Guacochito, material de arrastre, palas manuales, volquetas.

\footnotetext{
${ }^{1}$ Geólogo. Valledupar, Colombia. Correo: caliortegalahotmail.com

${ }^{2}$ Ingeniero de Minas, M. Sc. Gestión Ambiental y Energética en las Organizaciones, Universidad de La Guajira, Riohacha, Colombia. Correo: dinomancojarabaQigmail.com

${ }^{3}$ Geólogo, especialista en Minería a Cielo Abierto. Valledupar, Colombia. Correo: erojas@areandina.edu.co
} 


\section{Introducción}

El río Cesar tradicionalmente ha aportado material de construcción, específicamente material de arrastre, destinado a obras urbanísticas de la ciudad de Valledupar. Hasta el momento esta actividad se ha desarrollado sin ningún control o planeación, permitiendo así el deterioro ambiental y geotécnico de las riveras de los ríos mencionados.

El área de estudio pertenece a la cuenca del río Cesar, la cual limita con la Sierra Nevada de Santa Marta al occidente y la serranía del Perijá al oriente; está ubicada en la vecindad de la ciudad de Valledupar, capital del departamento del Cesar entre las siguientes coordenadas abarcando una superficie de 11,6 km2. (IGAC, 1996)

Tabla 1. Coordenadas del área de estudio

\begin{tabular}{|c|c|c|}
\hline Punto & Norte $\mathrm{X}$ & Este $\mathrm{Y}$ \\
\hline $\mathrm{A}$ & 1652000 & 1098500 \\
\hline $\mathrm{B}$ & 1655965 & 1102000 \\
\hline $\mathrm{C}$ & 1655965 & 1103000 \\
\hline $\mathrm{D}$ & 1655000 & 1104000 \\
\hline $\mathrm{E}$ & 1651150 & 1100500 \\
\hline
\end{tabular}

Fuente: elaboración propia

\section{Materiales y métodos}

La investigación se dirigió hacia el avance en el conocimiento de los parámetros geológico-mineros y ambientales que pueden influir en los procesos de estabilidad y vida del río Cesar en el sector norte de Guacoche-Guacochito.

Se recopiló la información existente sobre el área, específicamente los estudios geológicos, hidrológicos, monografías, atlas tales como Evolución geológica de la Sierra Nevada de Santa Marta (Tschanz y Marvin, 1974), Informe geológico preliminar de la cuenca del río Cesar (Ecopetrol, 1975), Atlas ambiental del departamento del Cesar (Ecocarbón- Corpocesar, 1996), Plan de Ordenamiento y Desarrollo Minero del Departamento del Cesar (Agemces, 1996), Impacto ambiental de la explotación de material de arrastre de los rios Cesar y Guatapuri (Concept Ltda., 1996), Adecuación materiales de arrastre en áreas de pequeña minería en los rios Cesar y Guatapurí (Alcaldía de Valledupar-Minercol, 2001), y se realizó una caracterización cualitativa y cuantitativa de los impactos realizados en explotación artesanal lecho del río Cesar en el sector norte de GuacocheGuacochito. 


\section{Resultados}

\section{Geología}

- Depósitos de terraza

Aflora a lo largo de la margen occidental del río Cesar, formando superficies ligeramente inclinadas, con pendientes menores de $4^{\circ}$. Corresponden a depósitos cuaternarios no consolidados que se manifiestan como un banco a manera de escalón que la separa de los depósitos de llanura de inundación (Q1li) (Ecocarbón- Corpocesar, 1996; Geología Norandina, 1980).

Litológicamente esta unidad está compuesta por arcillas plásticas de color marrón oscuro, hacia la parte superior se observa la presencia de materia orgánica (raíces), hacia la parte media y base se observan delgados niveles de limo de hasta $0,20 \mathrm{~m}$ de espesor, con la presencia continua de un delgado nivel costras cementadas de composición calcárea de escasos 0,05 m. El espesor medido de esta unidad varía de 2 a $8 \mathrm{~m}$ en cercanías al corregimiento de Guacochito.
Figura 1. Aluviones recientes

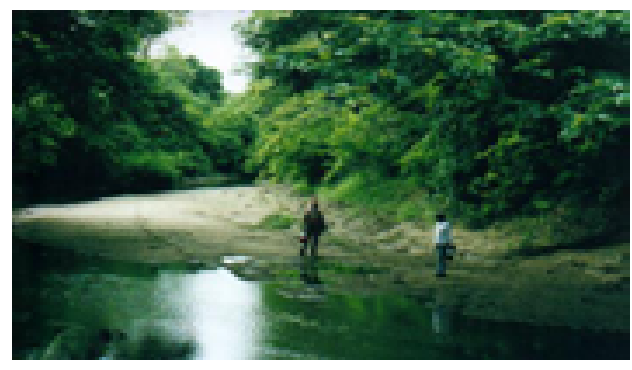

\section{Sitios de extracción existentes}

La principal fuente de extracción de material de arrastre en el río Cesar, se realiza sobre el mismo lecho del río, los depósitos de donde se extrae el material son lentejones irregulares de arena (Alcaldía de Valledupar-Minercol, 2002). Se realizó un recorrido por los sectores en los que se adelanta la extracción de arena ubicada en la margen izquierda del río Cesar, municipio de Valledupar.

Corregimiento de Guacochito. Este Corregimiento se localiza al NE de la zona urbana de Valledupar. El acceso a la zona se realiza por una carretera de segundo orden que en dirección NE y en una distancia de $16 \mathrm{~km}$, parte de Valledupar hasta este caserío.

En esta zona se extrae arena, la cual es explotada directamente del cauce del río por métodos artesanales adelantadas 
de forma manual sin ninguna tecnología ni diseño de laboreo minero. El verano es la época de mayor extracción. En el área se identificaron 5 sitios de extracción en el cauce del río.

Puerto Nueva Luz. Este sitio de Extracción se localiza al NE del corregimiento de Guacochito. El acceso al área se realiza por un carreteable de aproximadamente $1 \mathrm{~km}$ en mal estado que conduce directamente al área de interés. El área de extracción actual posee unos $2000 \mathrm{~m}^{2}$ inundados periódicamente durante las crecidas del río en épocas normales de invierno, lo cual ha generado morfológicamente llanuras, cauces abandonados, islas, etc., portadores de material sedimentado.

Puerto de Rogelio. Dista $800 \mathrm{~m}$ en dirección NE del caserío de Guacochito, consiste en un depósito de arenas ubicado en ambas márgenes del río Cesar, en una playa dejada en épocas de sequía. El área aproximada es de $1000 \mathrm{~m}^{2}$.

Puerto Miraflores. Se encuentra ubicado a $700 \mathrm{~m}$ al NE de Guacochito. El área de extracción actual posee unos $1000 \mathrm{~m}^{2}$ los cuales son inundados periódicamente durante las crecidas del río en épocas de invierno, lo cual ha generado, cauces abandonados, islas, etc., portadores de arena.
Puerto Guacochito. Dista $500 \mathrm{~m}$ al E del caserío. Abarca un área de 1500 $\mathrm{m}^{2}$. Consiste en un depósito de arenas dejadas por descenso de las aguas del río en épocas de sequía.

Puerto de Los Guerra. Está ubicado $700 \mathrm{~m}$ al SE del caserío de Guacochito.

Corregimiento de Guacoche. Ubicado al NE de la Ciudad de Valledupar. El acceso a la zona se realiza por una carretera de segundo orden que parte de Valledupar en dirección NE a una distancia de $14 \mathrm{~km}$.

En esta zona se extrae arena; explotada directamente del cauce del río por métodos artesanales, siendo el verano su época de mayor extracción.

Estas labores son adelantadas en forma manual sin ningún tipo de tecnología ni diseño de laboreo minero, ni seguridad ni la organización empresarial.

En el área se encontraron 4 puntos de extracción en el cauce del río así:

Puerto Martín Ramos. Este punto de extracción se encuentra ubicado a 1800 m. al NE de la cabecera corregimental de Guacoche. Tiene aproximadamente un área de $1200 \mathrm{~m}^{2}$.

Puerto de la Isla. Dista a $750 \mathrm{~m}$ al E de la población de Guacoche. Abarca un área aproximada de $1000 \mathrm{~m}^{2}$. 
Puerto Guacoche. Este punto de extracción está distante $200 \mathrm{~m}$ de Guacoche. Abarca un área de $2000 \mathrm{~m}^{2}$.

Puerto El Tabo. Dista $300 \mathrm{~m}$ al SE de Guacoche. El área de extracción tiene una superficie de $1000 \mathrm{~m}^{2}$.

\section{Situación minera y ambiental}

Situación legal en el área otorgada para estudio, solo se encuentran 2 solicitudes especiales de exploraciones ya canceladas y archivadas por la autoridad minera del departamento, debido entre otros al incumplimiento reiterado de las obligaciones contractuales adquiridas.

Tabla 2. Solicitudes mineras tramitadas ante la Secretaría Minas

\begin{tabular}{|c|c|c|c|c|c|}
\hline $\begin{array}{c}\text { Número del } \\
\text { Expediente }\end{array}$ & Mineral & $\begin{array}{c}\text { Tipo de } \\
\text { Solicitud }\end{array}$ & Titular & Corregimiento & $\begin{array}{c}\text { Estado } \\
\text { de la } \\
\text { Solicitud }\end{array}$ \\
\hline $099-20$ & $\begin{array}{c}\text { Material } \\
\text { de arrastre }\end{array}$ & $\begin{array}{c}\text { Licencia de } \\
\text { exploración }\end{array}$ & $\begin{array}{c}\text { J.A.C de } \\
\text { Guacochito }\end{array}$ & Guacochito & Cancelada \\
\hline $0105-20$ & $\begin{array}{c}\text { Material } \\
\text { de arrastre }\end{array}$ & $\begin{array}{c}\text { Licencia de } \\
\text { exploración }\end{array}$ & $\begin{array}{c}\text { Asociación } \\
\text { de Paleros de } \\
\text { Guacoche }\end{array}$ & Guacoche & Cancelada \\
\hline
\end{tabular}

En las tablas 3, 4, 5, 6, 7 se aprecia que los indicadores más afectados son aprovechamiento de material de arrastre, alteración del lecho del río y la pérdida de hábitats acuáticos. Los dos primeros indicadores, es factible que en la época de invierno fácilmente sean contrarrestados, mientras la pérdida de hábitats, será compensado naturalmente, con la formación de otros, en los momentos que no haya explotación (invierno) y en la actividad de cierre y abandono del proyecto (Canter, 1998; Concept Ltda, 1966). 
Tabla 3. Impactos cualitativos con explotación artesanal en el lecho del río Cesar

\begin{tabular}{|c|c|c|c|c|c|c|c|}
\hline \multicolumn{3}{|c|}{ Ecosistema } & \multicolumn{5}{|c|}{ Actividades impactantes* } \\
\hline $\begin{array}{l}\text { Compo- } \\
\text { nente }\end{array}$ & Elemento & Indicador & 1 & 2 & 3 & 4 & 5 \\
\hline \multirow{9}{*}{ Físico } & \multirow{3}{*}{ Lecho del río } & $\begin{array}{l}\text { Aprovechamiento material de } \\
\text { arrastre }\end{array}$ & & & & & \\
\hline & & Alteración lecho del río & & & & & \\
\hline & & Recuperación lecho del río & & & & & \\
\hline & \multirow{2}{*}{ Agua superficial } & Alteración calidad física & & & & & \\
\hline & & Alteración calidad organoléptica & & & & & \\
\hline & \multirow{2}{*}{$\begin{array}{l}\text { Suelos de } \\
\text { llanura }\end{array}$} & Contaminación por residuos & & & & & \\
\hline & & Compactación del perfil & & & & & \\
\hline & \multirow{2}{*}{ Aire } & Emisión de material particulado & & & & & \\
\hline & & Emisión de gases & & & & & \\
\hline \multirow{6}{*}{ Biótico } & \multirow{2}{*}{ Vegetación } & Sustracción de especies & & & & & \\
\hline & & Aprovechamiento forestal & & & & & \\
\hline & \multirow{4}{*}{ Fauna } & Reducción de especies & & & & & \\
\hline & & Desplazamiento de especies & & & & & \\
\hline & & Pérdida de habitas terrestres & & & & & \\
\hline & & Pérdida de habitas acuáticos & & & & & \\
\hline \multirow{2}{*}{ Social } & Cultural & Modificación del paisaje & & & & & \\
\hline & Económico & Oportunidad de empleo & & & & & \\
\hline
\end{tabular}

* 1) delimitación y construcción de trincheras; 2) excavación manual en lecho del río Cesar; 3) Formación de pilas de material de construcción; 4) cargue y transporte del material de construcción; 5) cierre y abandono. 
Tabla 4. Impactos cuantitativos por la delimitación y construcción de trincheras

\begin{tabular}{|c|c|c|c|c|c|c|c|c|c|c|c|c|c|}
\hline \multicolumn{3}{|c|}{ Ecosistema } & \multicolumn{11}{|c|}{ Criterio } \\
\hline $\begin{array}{c}\text { Com- } \\
\text { ponente }\end{array}$ & Elemento & Indicador & $\mathrm{C}$ & $\mathrm{Mg}$ & Co & $\mathrm{Pm}$ & $\mathrm{Dr}$ & $\mathrm{Rv}$ & $\operatorname{Re}$ & A & $\mathrm{Ti}$ & I & Total \\
\hline \multirow{9}{*}{ Físico } & \multirow{3}{*}{$\begin{array}{l}\text { Lecho del } \\
\text { río }\end{array}$} & $\begin{array}{l}\text { Aprovechamiento } \\
\text { material de arrastre }\end{array}$ & & & & & & & & & & & \\
\hline & & Alteración lecho del río & & & & & & & & & & & \\
\hline & & $\begin{array}{l}\text { Recuperación lecho } \\
\text { del río }\end{array}$ & & & & & & & & & & & \\
\hline & \multirow{2}{*}{$\begin{array}{c}\text { Agua } \\
\text { superficial }\end{array}$} & Alteración calidad física & - & 1 & 1 & 4 & 1 & 1 & 1 & 1 & 1 & 14 & \multirow[b]{2}{*}{14} \\
\hline & & $\begin{array}{l}\text { Alteración calidad } \\
\text { organoléptica }\end{array}$ & - & 1 & 1 & 4 & 1 & 1 & 1 & 1 & 1 & 14 & \\
\hline & \multirow{2}{*}{$\begin{array}{l}\text { Suelos de } \\
\text { llanura }\end{array}$} & $\begin{array}{l}\text { Contaminación por } \\
\text { residuos }\end{array}$ & & & & & & & & & & & \\
\hline & & Compactación del perfil & & & & & & & & & & & \\
\hline & \multirow[t]{2}{*}{ Aire } & $\begin{array}{l}\text { Emisión de material } \\
\text { particulado }\end{array}$ & & & & & & & & & & & \\
\hline & & Emisión de gases & & & & & & & & & & & \\
\hline \multirow{6}{*}{ Biótico } & \multirow{2}{*}{ Vegetación } & Sustracción de especies & & & & & & & & & & & \\
\hline & & Aprovechamiento forestal & - & 1 & 1 & 2 & 1 & 2 & 2 & 1 & 1 & 14 & 14 \\
\hline & \multirow{4}{*}{ Fauna } & Reducción de especies & & & & & & & & & & & \\
\hline & & $\begin{array}{l}\text { Desplazamiento de } \\
\text { especies }\end{array}$ & & & & & & & & & & & \\
\hline & & $\begin{array}{l}\text { Pérdida de habitat } \\
\text { terrestres }\end{array}$ & & & & & & & & & & & \\
\hline & & $\begin{array}{l}\text { Pérdida de habitat } \\
\text { acuáticos }\end{array}$ & & & & & & & & & & & \\
\hline \multirow{2}{*}{ Social } & Cultural & Modificación del paisaje & & & & & & & & & & & \\
\hline & Económico & Oportunidad de empleo & + & 1 & 1 & 4 & 1 & 1 & 2 & 4 & 4 & 21 & 21 \\
\hline
\end{tabular}


Tabla 5. Impactos cuantitativos por la excavación manual en lecho del río Cesar

\begin{tabular}{|c|c|c|c|c|c|c|c|c|c|c|c|c|c|}
\hline \multicolumn{3}{|c|}{ Ecosistema } & \multicolumn{11}{|c|}{ Criterio } \\
\hline Componente & Elemento & Indicador & $\mathrm{C}$ & $\mathrm{Mg}$ & $\mathrm{Co}$ & $\mathrm{Pm}$ & Dr & $\mathrm{Rv}$ & $\operatorname{Re}$ & A & $\mathrm{Ti}$ & I & Total \\
\hline \multirow{9}{*}{ Físico } & \multirow{3}{*}{$\begin{array}{l}\text { Lecho del } \\
\text { río }\end{array}$} & $\begin{array}{l}\text { Aprovechamiento } \\
\text { material de arrastre }\end{array}$ & - & 2 & 2 & 4 & 2 & 1 & 2 & 4 & 4 & 27 & \multirow{3}{*}{26} \\
\hline & & $\begin{array}{l}\text { Alteración lecho } \\
\text { del río }\end{array}$ & - & 2 & 1 & 4 & 2 & 1 & 2 & 4 & 4 & 25 & \\
\hline & & $\begin{array}{l}\text { Recuperación lecho } \\
\text { del río }\end{array}$ & & & & & & & & & & & \\
\hline & \multirow{2}{*}{$\begin{array}{c}\text { Agua } \\
\text { superficial }\end{array}$} & $\begin{array}{l}\text { Alteración calidad } \\
\text { física }\end{array}$ & - & 1 & 1 & 4 & 1 & 1 & 1 & 1 & 1 & 14 & \multirow{2}{*}{14} \\
\hline & & $\begin{array}{l}\text { Alteración calidad } \\
\text { organoléptica }\end{array}$ & - & 1 & 1 & 4 & 1 & 1 & 1 & 1 & 1 & 14 & \\
\hline & \multirow{2}{*}{$\begin{array}{l}\text { Suelos de } \\
\text { llanura }\end{array}$} & $\begin{array}{l}\text { Contaminación por } \\
\text { residuos }\end{array}$ & & & & & & & & & & & \\
\hline & & $\begin{array}{l}\text { Compactación del } \\
\text { perfil }\end{array}$ & & & & & & & & & & & \\
\hline & \multirow{2}{*}{ Aire } & $\begin{array}{l}\text { Emisión de material } \\
\text { particulado }\end{array}$ & & & & & & & & & & & \\
\hline & & Emisión de gases & & & & & & & & & & & \\
\hline \multirow{6}{*}{ Biótico } & \multirow{2}{*}{ Vegetación } & Sustracción de especies & & & & & & & & & & & \\
\hline & & $\begin{array}{l}\text { Aprovechamiento } \\
\text { forestal }\end{array}$ & & & & & & & & & & & \\
\hline & \multirow{4}{*}{ Fauna } & Reducción de especies & - & 1 & 1 & 2 & 2 & 2 & 2 & 4 & 1 & 18 & \multirow{4}{*}{18} \\
\hline & & $\begin{array}{l}\text { Desplazamiento de } \\
\text { especies }\end{array}$ & - & 1 & 1 & 2 & 2 & 1 & 2 & 1 & 4 & 17 & \\
\hline & & $\begin{array}{l}\text { Pérdida de habitat } \\
\text { terrestres }\end{array}$ & - & 1 & 1 & 1 & 1 & 2 & 2 & 1 & 1 & 13 & \\
\hline & & $\begin{array}{l}\text { Pérdida de habitat } \\
\text { acuáticos }\end{array}$ & - & 1 & 2 & 4 & 2 & 2 & 2 & 4 & 4 & 25 & \\
\hline \multirow{2}{*}{ Social } & Cultural & Modificación del paisaje & & & & & & & & & & & \\
\hline & Económico & Oportunidad de empleo & + & 1 & 1 & 4 & 2 & 1 & 2 & 1 & 4 & 17 & 17 \\
\hline
\end{tabular}


Tabla 6. Impactos cuantitativos por la formación de pilas de material de construcción

\begin{tabular}{|c|c|c|c|c|c|c|c|c|c|c|c|c|c|}
\hline \multicolumn{3}{|c|}{ Ecosistema } & \multicolumn{11}{|c|}{ Criterio } \\
\hline Componente & Elemento & Indicador & $\mathrm{C}$ & $\mathrm{Mg}$ & $\mathrm{Co}$ & $\mathrm{Pm}$ & Dr & $\mathrm{Rv}$ & $\mathrm{Re}$ & A & $\mathrm{Ti}$ & I & Total \\
\hline \multirow{9}{*}{ Físico } & \multirow{3}{*}{$\begin{array}{l}\text { Lecho del } \\
\quad \text { río }\end{array}$} & $\begin{array}{l}\text { Aprovechamiento } \\
\text { material de arrastre }\end{array}$ & & & & & & & & & & & \\
\hline & & Alteración lecho del río & & & & & & & & & & & \\
\hline & & $\begin{array}{l}\text { Recuperación lecho del } \\
\text { río }\end{array}$ & & & & & & & & & & & \\
\hline & \multirow[b]{2}{*}{$\begin{array}{c}\text { Agua su- } \\
\text { perficial }\end{array}$} & Alteración calidad física & - & 1 & 1 & 4 & 1 & 1 & 1 & 1 & 1 & 14 & \multirow[b]{2}{*}{14} \\
\hline & & $\begin{array}{l}\text { Alteración calidad } \\
\text { organoléptica }\end{array}$ & - & 1 & 1 & 4 & 1 & 1 & 1 & 1 & 1 & 14 & \\
\hline & \multirow{2}{*}{$\begin{array}{l}\text { Suelos de } \\
\text { llanura }\end{array}$} & $\begin{array}{l}\text { Contaminación } \\
\text { por residuos }\end{array}$ & & & & & & & & & & & \\
\hline & & Compactación del perfil & & & & & & & & & & & \\
\hline & \multirow[t]{2}{*}{ Aire } & $\begin{array}{l}\text { Emisión de material } \\
\text { particulado }\end{array}$ & & & & & & & & & & & \\
\hline & & Emisión de gases & & & & & & & & & & & \\
\hline \multirow{6}{*}{ Biótico } & \multirow{2}{*}{$\begin{array}{l}\text { Vegeta- } \\
\text { ción }\end{array}$} & Sustracción de especies & & & & & & & & & & & \\
\hline & & Aprovechamiento forestal & & & & & & & & & & & \\
\hline & \multirow{4}{*}{ Fauna } & Reducción de especies & - & 1 & 1 & 2 & 2 & 2 & 2 & 4 & 1 & 18 & \multirow{4}{*}{16} \\
\hline & & $\begin{array}{l}\text { Desplazamiento de es- } \\
\text { pecies }\end{array}$ & - & 1 & 1 & 2 & 2 & 1 & 2 & 1 & 4 & 17 & \\
\hline & & $\begin{array}{l}\text { Pérdida de habitas te- } \\
\text { rrestres }\end{array}$ & - & 1 & 1 & 1 & 1 & 2 & 2 & 1 & 1 & 13 & \\
\hline & & $\begin{array}{l}\text { Pérdida de habitas acuá- } \\
\text { ticos }\end{array}$ & & & & & & & & & & & \\
\hline \multirow[b]{2}{*}{ Social } & Cultural & Modificación del paisaje & - & 1 & 1 & 2 & 2 & 1 & 2 & 4 & 4 & 20 & 20 \\
\hline & $\begin{array}{l}\text { Econó- } \\
\text { mico }\end{array}$ & Oportunidad de empleo & + & 1 & 1 & 4 & 2 & 1 & 2 & 1 & 4 & 17 & 17 \\
\hline
\end{tabular}


Tabla 7. Impactos cuantitativos por el cargue y transporte del material de construcción

\begin{tabular}{|c|c|c|c|c|c|c|c|c|c|c|c|c|c|}
\hline \multicolumn{3}{|c|}{ Ecosistema } & \multicolumn{11}{|c|}{ Criterio } \\
\hline Componente & Elemento & Indicador & $\mathrm{C}$ & $\mathrm{Mg}$ & Co & Pm & $\operatorname{Dr}$ & $\mathrm{Rv}$ & $\operatorname{Re}$ & A & $\mathrm{Ti}$ & I & Total \\
\hline \multirow{9}{*}{ Físico } & \multirow{3}{*}{$\begin{array}{l}\text { Lecho del } \\
\text { río }\end{array}$} & $\begin{array}{l}\text { Aprovechamien- } \\
\text { to material de } \\
\text { arrastre }\end{array}$ & & & & & & & & & & & \\
\hline & & $\begin{array}{l}\text { Alteración lecho } \\
\text { del río }\end{array}$ & & & & & & & & & & & \\
\hline & & $\begin{array}{l}\text { Recuperación } \\
\text { lecho del río }\end{array}$ & & & & & & & & & & & \\
\hline & \multirow{2}{*}{$\begin{array}{c}\text { Agua } \\
\text { superficial }\end{array}$} & $\begin{array}{l}\text { Alteración } \\
\text { calidad física }\end{array}$ & - & 1 & 1 & 4 & 1 & 1 & 1 & 1 & 4 & 17 & \multirow{2}{*}{17} \\
\hline & & $\begin{array}{l}\text { Alteración cali- } \\
\text { dad organoléptica }\end{array}$ & - & 1 & 1 & 4 & 1 & 1 & 1 & 1 & 4 & 17 & \\
\hline & \multirow{2}{*}{$\begin{array}{l}\text { Suelos de } \\
\text { llanura }\end{array}$} & $\begin{array}{l}\text { Contaminación } \\
\text { por residuos }\end{array}$ & - & 1 & 2 & 2 & 1 & 1 & 1 & 1 & 1 & 14 & \multirow{2}{*}{13} \\
\hline & & $\begin{array}{l}\text { Compactación del } \\
\text { perfil }\end{array}$ & - & 1 & 1 & 1 & 1 & 1 & 1 & 1 & 1 & 11 & \\
\hline & \multirow[t]{2}{*}{ Aire } & $\begin{array}{l}\text { Emisión de } \\
\text { material } \\
\text { particulado }\end{array}$ & - & 1 & 1 & 4 & 1 & 1 & 1 & 1 & 4 & 18 & \multirow[t]{2}{*}{18} \\
\hline & & Emisión de gases & - & 1 & 1 & 4 & 1 & 1 & 1 & 1 & 4 & 18 & \\
\hline \multirow{6}{*}{ Biótico } & \multirow{2}{*}{ Vegetación } & $\begin{array}{l}\text { Sustracción de } \\
\text { especies }\end{array}$ & & & & & & & & & & & \\
\hline & & $\begin{array}{l}\text { Aprovechamiento } \\
\text { forestal }\end{array}$ & & & & & & & & & & & \\
\hline & \multirow{4}{*}{ Fauna } & $\begin{array}{l}\text { Reducción de } \\
\text { especies }\end{array}$ & - & 1 & 1 & 2 & 2 & 2 & 2 & 4 & 1 & 18 & \multirow{4}{*}{18} \\
\hline & & $\begin{array}{l}\text { Desplazamiento } \\
\text { de especies }\end{array}$ & - & 1 & 1 & 2 & 2 & 1 & 2 & 1 & 4 & 17 & \\
\hline & & $\begin{array}{l}\text { Pérdida de habitas } \\
\text { terrestres }\end{array}$ & - & 1 & 1 & 1 & 1 & 2 & 2 & 1 & 1 & 13 & \\
\hline & & $\begin{array}{l}\text { Pérdida de habitas } \\
\text { acuáticos }\end{array}$ & - & 1 & 2 & 4 & 2 & 2 & 2 & 4 & 4 & 25 & \\
\hline \multirow{2}{*}{ Social } & Cultural & $\begin{array}{l}\text { Modificación del } \\
\text { paisaje }\end{array}$ & - & 1 & 1 & 4 & 2 & 4 & 2 & 4 & 1 & 22 & 22 \\
\hline & Económico & $\begin{array}{l}\text { Oportunidad de } \\
\text { empleo }\end{array}$ & + & 1 & 1 & 4 & 2 & 2 & 2 & 1 & 4 & 20 & 20 \\
\hline
\end{tabular}




\section{Sistema de explotación}

\section{Corregimiento de Guacochito}

\section{Método de explotación. Puertos Nueva Luz, de Rogelio, Miraflores, Guacochito y de Los Guerra}

El mineral explotado es arena. El método utilizado para su extracción es artesanal, se realiza mediante el uso de palas manuales o azadón, las cuales extraen el material de los cauces abandonados en épocas de verano, de allí cargan directamente a la volqueta figura 2 .

Las labores ejecutadas no obedecen a ningún tipo de diseño o plan de trabajo minero, así como tampoco a las normas mínimas de seguridad. Se emplea el método de minería a cielo abierto de avance sobre las playas y depósitos de material dentro del río.

Figura 2. Equipos de traslado de material

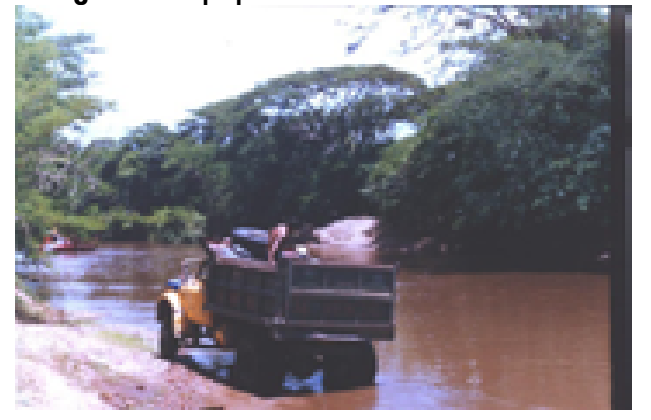

Las áreas de extracción no son de magnitudes considerables; a pesar de que las extracciones son llevadas a cabo aproximadamente desde hace diez años, la condición de ocasión y desorganización les dan la categorización de explotaciones incipientes (Concept Ltda, 1996).

Los puntos de extracción se localizan en cauces abandonados en época de descenso de las aguas del río Cesar; el mecanismo es que al llegar la época de verano (el cual tiene una durabilidad aproximada en promedio de cinco meses y medio), mediante el uso de palas manuales, se extrae el material de la forma ya descrita y posteriormente al llegar el invierno el material extraído es renovado por la inundación del río (Agemces, 1996).

Las labores ejecutadas por el personal minero involucrado son estrictamente de extracción y cargue. No existe una comunidad legalmente organizada para la extracción, aunque los encargados de ella (paleros) dicen estarlo; la realidad es que el dueño de volqueta contacte al personal palero ya reconocido localmente y se le pague por el trabajo solicitado. El volumen promedio extraído en temporadas de verano es de $30 \mathrm{~m}^{3} / \mathrm{mes}$ de arena. 


\section{Equipos o maquinaria}

Tal como se mencionó anteriormente, la extracción es adelantada de una forma artesanal y rudimentaria, el equipo consta de:

- Azadones y palas manuales para la extracción o cargue.

- Volquetas con capacidad de 6 m3 para el transporte.

\section{Personal}

El personal involucrado en el laboreo minero de los puertos del Corregimiento de Guacochito es de 35 personas aproximadamente. Dado lo ocasional de la explotación, alternan la extracción de material de arrastre con la siembra o pesca.

\section{Corregimiento de Guacoche}

\section{Método de explotación. Puertos Martín Ramos, de la Isla, Guacoche y El Tabo}

La extracción en estos sitios se realiza de una forma artesanal y rudimentaria, utilizando para ello azadones y palas manuales. El mecanismo es el mismo que se utiliza en la mayoría de los frentes detectados a lo largo del río Cesar, se extrae por pala manual, depositando el material extraído en unos baldes o canecas con el fondo perforado (mecanismo de drenaje) y de allí a las volquetas.

El material se extrae en áreas que ya han sido recargadas por los aportes en la creciente del río en épocas de sequía.

Se emplea el método de minería a cielo abierto de avance sobre las playas y depósitos de material dentro del río. El volumen promedio extraído en temporadas normales de verano es de $1400 \mathrm{~m} 3 /$ mes de arena.

\section{Equipos o maquinaria}

El equipo utilizado, marca en gran parte el grado de tecnológica del sistema de extracción. En el sector de Guacoche el equipo es rudimentario y la extracción adelantada está catalogada como artesanal. El equipo utilizado es:

- Azadones y palas manuales para la extracción o cargue.

- Baldes o canecas para el cargue.

- Volquetas con capacidad de 6 m3.

Personal. El personal involucrado en el laboreo minero de los puertos del corregimiento de Guacoche es de 56 personas aproximadamente. Dado lo ocasional de la explotación, alternan la 
extracción de material de arrastre con la siembra o pesca.

Secuencia de la explotación. Las explotaciones que se ubican en el cauce del río Cesar extraen arena de manera ocasional o discontinua, y está en función de la época de invierno-verano.

\section{Seguridad minera}

El personal involucrado en las actividades de extracción de arena en los corregimientos de Guacoche y Guacochito laboran con mínimas condiciones de seguridad industrial, razón por la cual están expuestos a toda clase de accidentes que lo imposibilitan para la realización de su labor diaria. Por lo tanto, se pudo comprobar que:

- Carecen de un programa de salud ocupacional.

- Carecen de reglamento de higiene y seguridad industrial.

- Carecen de los elementos básicos de protección personal.

- En los equipos de acarreo, no disponen de extintores.

No cuentan con un botiquín de primeros auxilios.

Además, se identificaron los riesgos más comunes a que están expuestos los mineros de este sector (ver tabla 8).
Tabla 8. Riesgos a que están expuestos los mineros

\begin{tabular}{|l|l|}
\hline \multicolumn{1}{|c|}{ Riesgos } & \multicolumn{1}{c|}{ Originado por } \\
\hline Físicos & $\begin{array}{l}\text { Altas temperaturas, rayos } \\
\text { ionizantes }\end{array}$ \\
\hline Químicos & $\begin{array}{l}\text { Material particulado (polvos, } \\
\text { sílices, gases de combustión in- } \\
\text { terna) }\end{array}$ \\
\hline Mecánicos & $\begin{array}{l}\text { Manejo de herramientas, golpes, } \\
\text { contusiones }\end{array}$ \\
\hline Ergonómicos & $\begin{array}{l}\text { Malas posturas en el manejo de las } \\
\text { herramientas de trabajo }\end{array}$ \\
\hline Psicosociales & $\begin{array}{l}\text { Alteración del orden público en la } \\
\text { zona, stress, falta de incentivos }\end{array}$ \\
\hline Biológicos & $\begin{array}{l}\text { Hongos, virus, bacterias, animales } \\
\text { (serpientes, babillas y rayas) y } \\
\text { plantas }\end{array}$ \\
\hline
\end{tabular}

Fuente: elaboración propia

\section{Conclusiones}

Las explotaciones de material de arrastre en esta parte del río Cesar se adelantan dentro del cauce en forma rudimentaria, sin ninguna planificación minera o ambiental. Dichas explotaciones solo se adelantan en la temporada de verano o de poca precipitación, las cuales no inciden de forma significativa en la estabilidad del cauce, puesto que no sobrepasan su capacidad de regeneración anual.

Existe un yacimiento de arcilla en la zona de estudio, que es explotado incipientemente, se podría realizar una 
minería técnica y ambientalmente sostenible, para lo cual se necesita un plan de manejo ambiental, de esta forma la explotación estará acorde con la gestión ambiental y el desarrollo sostenible.

\section{Referencias}

Agemces (1996). Plan de Ordenamiento y Desarrollo Minero del Departamento del Cesar.

Alcaldía de Valledupar-Minercol (2002). Adecuación de materiales de arrastre de los rios Cesar y Guatapuri. Informe Convenio 026-2001. Valledupar, Colombia.

Canter, L. (1998). Manual de evaluación de impacto ambiental. Técnicas para la elaboración de los estudios de impacto. MacGraw Hill.
Concept Ltda. (1996). Impacto ambiental de la explotación de material de arrastre de los ríos Cesar y Guatapurí.

Ecocarbón-Corpocesar (1996). Atlas ambiental del departamento del Cesar.

Ecopetrol (1975). Informe geológico preliminar de la cuenca del río Cesar. Bogotá, D.C.

Geología Norandina (1980). Elementos tectónicos del valle del río Cesar.

Instituto Geográfico Agustín Codazzi (1996). Características geográficas del departamento del Cesar. Bogotá, D.C.

Ingeominas (1995). Estudio hidrogeológico y ambiental del departamento del Cesar. Bogotá D.C.

Tschanz, C. y Marvin, R. (1974). Evolución geológica de la Sierra Nevada de Santa Marta. 